\title{
A new species and an updated checklist of the genus Spogostylum Macquart (Bombyliidae: Diptera) from Egypt
}

\author{
Magdi S. El-Hawagry(D)
}

\begin{abstract}
Species of the genus Spogostylum are ectoparasitoids of solitary bees and wasps (order: Hymenoptera), Meloidae (order: Coleoptera), and immature stages of Pyralidae (order: Lepidoptera). Some species were also recorded as predators of egg pods of Acrididae (order: Orthoptera). Spogostylum niphasoides sp. nov. was collected from South Sinai, Egypt. It is described in the present study where it differs from closely related species in having all hairs and bristles mostly white, except some few hairs on outer side of pedicel, short spines on legs, and short hairs on costal margin of wing which are black. Also, antennae and legs mostly yellowish-brown, tibial spines short, about half the tibial width, and the male genitalia are obviously distinctive, having the aedeagal sheath with a broad and complicated tip, enclosing the aedeagal tip. An updated checklist of the Egyptian Spogostylum spp. is provided.
\end{abstract}

Keywords: Bee flies, Ectoparasitoides, Spogostylum niphasoides sp. nov., Efflatoun's collection, Sinai, List of species

\section{Background}

Bombyliidae, also known as "Bee flies," is one of the largest families of Diptera, containing about 4800 taxonomically valid species occur on all continents, except Antarctica and also many oceanic islands. They are typically and most frequently encountered in arid and semiarid environments, and constitute a high percentage of the diversity of flies in the most desert regions of the Earth (Hull 1973 and Evenhuis and Greathead, 2015).

As larvae, the vast majority of Bombyliidae are ectoparasitoids on the immatures of holometabolous insects, and a few species are known to prey on the egg pods of orthopterans. Consequently, they are thought to have potential as biological control agents (Yeates and Greathead 1997; Dils and Özbek 2006; El-Hawagry 2015 and Evenhuis and Greathead 2015).

Adult bombyliids are showy flower visitors and often act as the main pollinators of many flowering plant species, especially those occurring in the more desert environments. Individuals can often be seen on rocks or twigs sunning themselves or feeding on a variety of flowering plants, and the majority of adults are nectar feeders. Females are obligate pollen feeders, obtaining

Correspondence: elhawagry@gmail.com

Entomology Department, Faculty of Science, Cairo University, Giza, Egypt pollen as a necessary requirement for the nourishment of developing ova (Kits et al. 2008 and Evenhuis and Greathead 2015).

Species of the genus Spogostylum are ectoparasitoids of solitary bees and wasps (order: Hymenoptera), Meloidae (order: Coleoptera), and immature stages of Pyralidae (order: Lepidoptera). Some species were also recorded as predators of egg pods of Acrididae (order: Orthoptera) (Greathead 1963 and Yeates and Greathead 1997).

The genus Spogostylum is one of the moderately specious genera within the family Bombyliidae, with about 80 species worldwide. Its species are distributed mainly on the Palaearctic and Afrotropical Regions, with a few records from the Oriental Region (Evenhuis and Greathead 2015).

Ecologists divide Egypt into eight ecological zones, namely, Coastal Strip, Lower Nile Valley and Delta, Upper Nile Valley, Fayoum, Eastern Desert, Western Desert, Sinai, and Gebel Elba (Fig. 1). All these zones but one have greater affiliation to the Palaearctic Region, whereas, the Gebel Elba ecological zone, the southeastern triangle of Egypt, has greater affiliation to the Afrotropical Region (El-Hawagry and Gilbert 2014).

In Egypt, El-Hawagry et al. (2000) and El-Hawagry (2002) keyed and described 14 Spogostylum spp., namely, 


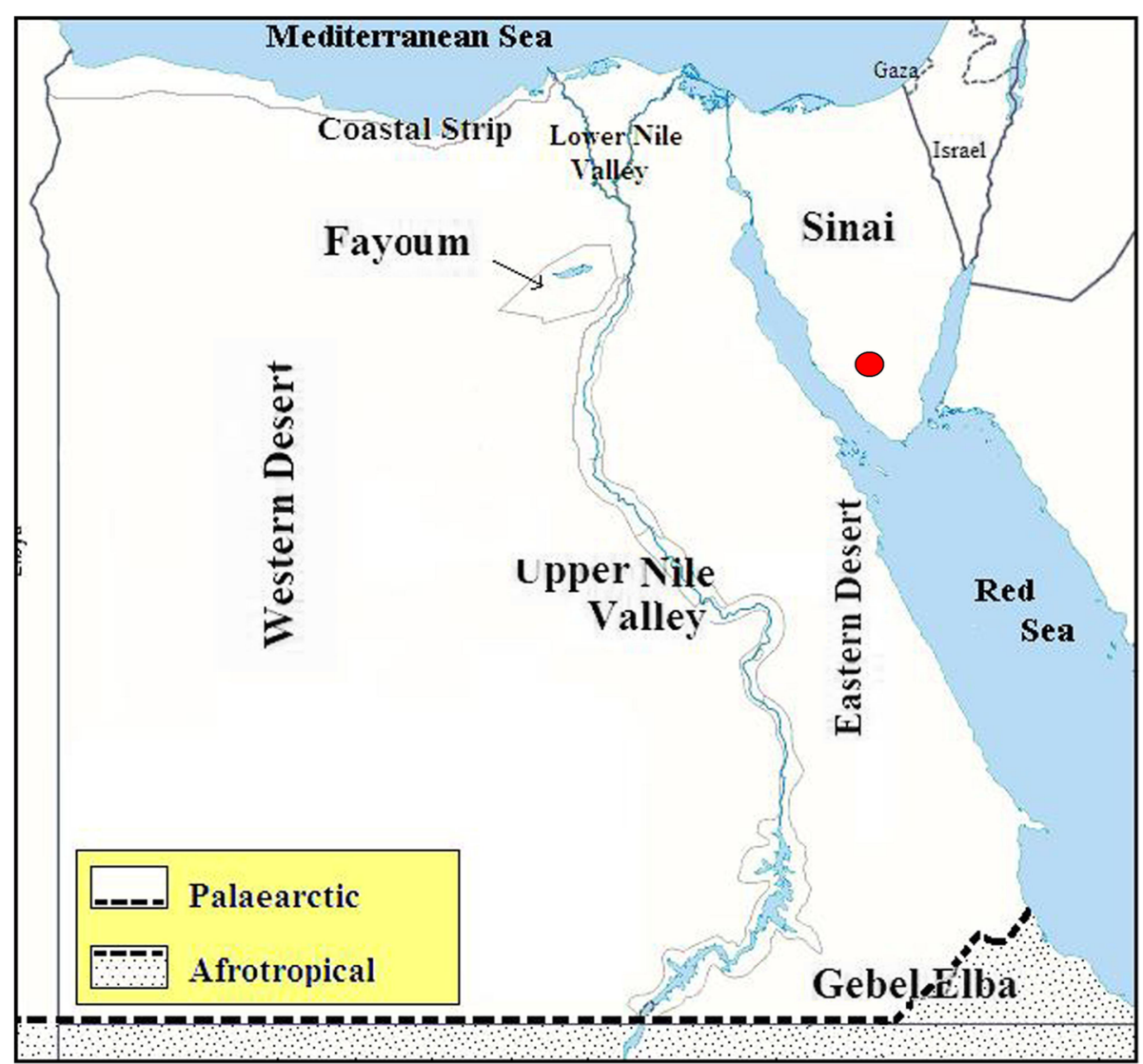

Fig. 1 Map of Egypt showing the collecting locality (modified from El-Hawagry and Gilbert 2014)

S. bisniphas (Bezzi, 1925), S. candidum (Sack, 1909), S. efflatouni Paramonov, 1957, S. griseipenne (Macquart, 1850), S. hamadnallahi El-Hawagry, 2002, S. hippolyta (Wiedemann, 1828), S. incisurale (Macquart, 1840), S. isis (Meigen, 1820), S. niphas (Hermann, 1907), S. ocyale (Wiedemann, 1828), S. sordidum Sack, 1909, S. tripunctatum (Pallas in Wiedemann 1818), S. ventrale Bezzi, 1924 and S. volitans Wiedemann, 1828. The genus was recorded from all Egyptian ecological zones as defined by El-Hawagry and Gilbert (2014), and frequently from Eastern Desert and Sinai.

Specimens of the present species have been found in Efflatoun's collection, Entomology Department, Faculty of Science, Cairo University (EFC), Egypt amongst some unidentified specimens collected from South Sinai (Fig. 1) by Efflatoun Bey. According to the Egyptian key of ElHawagry et al. (2000) and Saudi Arabian key of Greathead (1980), the specimens are closely allied to $S$. niphas (Hermann, 1907), S. bisniphas (Bezzi, 1925) and S. niphoides Greathead, 1980, however, they differ in that antennae and legs mostly yellowish-brown, all hairs and bristles on frons are white and maybe mixed with few slightly yellowishwhite hairs at upper half, abdomen devoid of black hairs and bristles, and tibial spines short, about half the tibial width. Only some few hairs on outer side of pedicel, short spines on legs, and short hairs on costal margin of wing are black. Also, the male genitalia are obviously distinctive, having the aedeagal sheath with a broad and complicated tip, enclosing the tip of aedeagus.

\section{Material and methods}

This description is based on two museum specimens in the Efflatoun's collection, Entomology Department, Faculty of Science, Cairo University (EFC), Egypt. The famed British bee fly taxonomist late Dr. David Greathead (died in 2006) checked these specimens and commented to me (a personal communication) that they seem to be new. Recently, I rechecked and dissected the specimens and found them obviously new.

The genitalia were prepared by dissecting the terminal abdominal segments and then heated in $10 \% \mathrm{KOH}$ for $20 \mathrm{~min}$. Following maceration, the genitalia were washed and then dissected in distilled water. They were stored in glycerin for microscopic examination and illustration. Dissected genitalia were placed in a genitalia vial containing glycerin and were pinned beneath the identification label. 


\section{Results and discussion}

Spogostylum niphasoides sp. nov.

\section{Description}

Male (holotype) (Fig. 2). Relatively medium to large-sized robust species, body length is about $13 \mathrm{~mm}$ and wing length is about $13.2 \mathrm{~mm}$. Head. Black in ground color; frons white dusted, with upper frons narrowed, about two times as wide as ocellar tubercle, all frons covered with pure white hairs, becoming slightly yellowish at upper frons; face densely covered with shaggy long pure white hairs; antennae $1 \mathrm{~mm}$ in length, yellowish-brown to brown at upper half of scape, lower half of pedicel and narrow apical part of flagellum, dark brown at broad lower base of flagellum, upper half of pedicel and lower half of scape; lower base of flagellum dusted white; hairs of antennae long white on scape, relatively short white on pedicel mixed with few black ones at outer side; scape about two times as long as and slightly wider than pedicel. Thorax. Glossy black in ground color, covered with shaggy long white hairs and fine short hairs, becoming slightly yellowish at central parts of scutum and scutellum; bristles of scutum and scutellum white, except yellowish brown supra-alar bristles; wings hyaline with very faint yellowish basicostal infuscation and whitish costal cell (c); veins dark brown except yellowish subcostal vein $(\mathrm{Sc})$ and humeral cross-vein (h); base of costal vein white dusted, with short black hairs; costal vein $(C)$ with shorter black hairs along margin; stem vein white dusted; anal cell (cup) narrowly open at wing margin, with opening about half length of posterior cross-vein (bm-cu) [in $S$. niphas, opening of cup relatively narrower, about third length of bm-cu or less]; halters yellowish, dusted white especially at tip of knob; legs yellowish-brown except the last tarsomeres of fore and middle legs, and all tarsomeres of hind legs which are brown; all legs covered with white scales and fine hairs, with short black bristles, bristles on tibia about half tibial width in length. Abdomen. Tergites glossy black in ground color with reddish-brown posterior borders, covered with white scaly hairs and long silky white hairs, becoming more dense and longer at sides and posterior margins, forming transverse bands almost on all tergites; some yellowish to brown fine hairs, and scaly hairs may also present mixed with white scaly hairs of white bands at margins of tergites and on center of second tergite; posterior tergite densely covered with broader scales and longer silky white hairs; gonocoxites truncate, triangular; gonostyli broad at base, with long curved apical part, constricted between broad base and long apical part, with small outer swelling covered with long hairs; aedeagal sheath is slightly longer than and

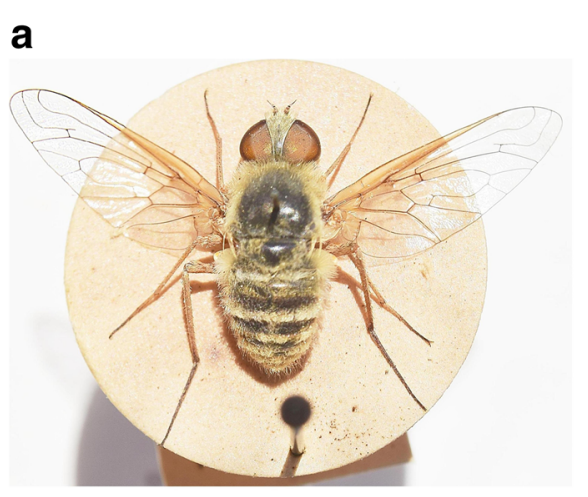

b

C

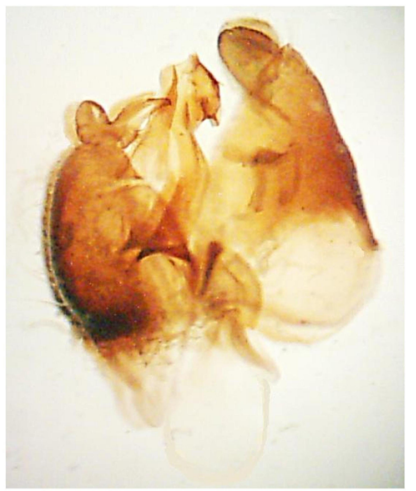

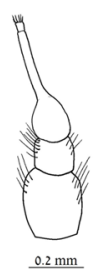

d

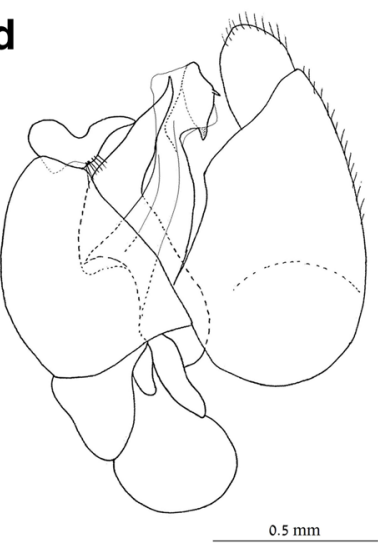

Fig. 2 Spogostylum niphasoides sp. nov. a Habitus. b Left antenna. c, d Male genitalia, lateral view 
enclosing aedeagus, with a broad complicated tip having two thorn-like dark spines directed antero-dorsally and located at proximal border of tip complex, and two smaller spines dorsally approximately at middle of tip complex; from lateral view, tip complex of aedeagal sheath seems semi-quadrangular, more sclerotized and darker in color dorsally, less sclerotized and lighter in color ventrally.

Female unknown.

Material examined. Holotype $\hat{\partial}$, Wadi Garagneyia (South Sinai), VI-VIII.42 (Efflatoun); paratype $\sigma^{\hat{N}}$ (in a poor condition), same data as holotype; all preserved in EFC.

\section{An updated checklist of Spogostylum spp. in Egypt}

Spogostylum bisniphas (Bezzi, 1925)

Distribution: PA: Egypt.

Egyptian localities: Eastern Desert: Wadi Dar ElMaskhara, Wadi Garawi, Wadi Hoff, Wadi Rishrash, Wadi Um-Girfan.

Dates of collection: April to June.

Spogostylum candidum (Sack, 1909)

Distribution: AF: Egypt [as "Gebel Elba"], United Arab Emirates. OR: Pakistan. PA: Egypt, Iran, Saudi Arabia, Turkey.

Egyptian localities: Eastern Desert: Abu-Sueir, Geneifa, Wadi Garawi, Wadi Murrah; Sinai: El-Arish, Bir Tarfah, Gebel Moussa, Hagar Bardeyia, Rafah, Wadi El-Arbaein, Wadi El-Rabba, Wadi Firan, Wadi Garagneyia, Wadi Isla, El-Zawatein; Fayoum; Gebel Elba.

Dates of collection: March to August.

Spogostylum efflatouni Paramonov, 1957

Spongostylum sergeiae Hull, 1973.

Distribution: PA: Egypt.

Egyptian localities: Eastern Desert: Wadi Digla.

Dates of collection: April to June.

Spogostylum griseipenne (Macquart, 1850)

Distribution: AF: Mauritania, Niger, United Arab Emirates. PA: Egypt, Iraq, Israel, Libya, Palestine (West Bank), Saudi Arabia, Tunisia.

Egyptian localities: Lower Nile Valley: Ebn Salam (Mansourah);Western Desert: Kharga; Fayoum: Kom Osheem.

Dates of collection: April to November.

Spogostylum hamadnallahi El-Hawagry, 2002

Distribution: PA: Egypt.

Egyptian localities: Sinai: Wadi Garagneyia.

Dates of collection: August.

Spogostylum hippolyta (Wiedemann, 1828)

Argyromoeba dedecor Hermann, 1907.

Anthrax villosa Klug in Hull, 1973. Nomen nudum.

Distribution: AF: Eritrea, Gambia, Guinea, Mali, Mauritania, Senegal, Sudan. PA: Egypt, Iran, Israel, Libya, Tajikistan, Turkey, Turkmenistan.
Egyptian localities: Coastal Strip: Hammam; Western Desert: Kharga; Sinai: Moweilah.

Dates of collection: September.

Spogostylum incisurale (Macquart, 1840)

Anthrax biappendiculata Macquart, 1855.

Anthrax mixta Loew, 1860.

Molybdamoeba incisuralis var. inquirenda Bezzi, 1912.

Argyramoeba incisuralis f. aridicola Hesse, 1956.

Argyramoeba incisuralis F. glaucescens Hesse, 1956.

Argyramoeba incisuralis f. fumosa Hesse, 1956.

Distribution: AF: Botswana, Egypt [as "Gebel Elba"], Lesotho, Malawi, Mozambique, Namibia, South Africa, Tanzania, Uganda, Zambia, Zimbabwe. PA: Egypt.

Egyptian localities: Coastal Strip: Alexandria, Nuzha, Ramleh; Lower Nile Valley: Abu-Rawash, Barrage, Borgash, Faraskour, KafrHakim, Katta, Kirdassa, Mansouriah, Ezbet Nakhl; Eastern Desert: Gebel Asfar, Ismailia, Wadi Garawi, Wadi Um-Elik; Fayoum: Kom Osheem; Sinai: Wadi El-Lega, Wadi Firan; Gebel Elba.

Dates of collection: April to September.

Spogostylum isis (Meigen, 1820)

Anthrax subnotata Walker, 1871.

Distribution: PA: Algeria, Armenia, Austria, Azerbaijan, Belgium, Croatia, Cyprus, Egypt, France, Greece, Gruzia, Israel, Italy, Kazakhstan, Kyrgyz Republic, Libya, Macedonia, Malta, Morocco, Portugal, Saudi Arabia, Spain, Syria, Tajikistan, Tunisia, Turkey, Turkmenistan, Uzbekistan, Yugoslavia.

Egyptian localities: Coastal Strip: Mariout; Lower Nile Valley: Kafr Hakim, Kirdassa; Eastern Desert: Abu-Sueir, Fayed, Geneifa, Wadi Gharagid, Wadi Ibtadi, Wadi UmGirfan, Wadi Zohleiga; Sinai: Wadi El-Arbaein, Wadi Isla, Wadi Tlah.

Dates of collection: April to August.

Spogostylum niphas (Hermann, 1907)

Spongostylum niphas var. bilineata Engel, 1936.

Distribution: AF: Eritrea, Mauritania, Oman, Somalia,

Yemen. OR: Pakistan.PA: Egypt, Israel, Saudi Arabia, Tajikistan, Turkey, Turkmenistan.

Egyptian localities: Coastal Strip: Mariout; Lower Nile Valley: Barrage, Helwan, Mansouriah, Tisfa; Eastern Desert: Wadi Garawi, Wadi Girfan, Wadi Ibtadi.

Dates of collection: April to August.

Spogostylum niphasoides sp. nov.

Distribution: PA: Egypt.

Egyptian localities: Sinai: Wadi Garagneyia (South Sinai).

Dates of collection: June to August.

Spogostylum ocyale (Wiedemann, 1828)

Anthrax umbra Walker, 1849.

Spogostylum arugotense Zaitzev, 1997.

Distribution: AF: Oman, Somalia, Sudan, United Arab Emirates, Yemen. PA: Egypt, Iran, Israel, Jordan, Libya, Palestine (West Bank), Saudi Arabia. 
Egyptian localities: Coastal Strip: Amriah, Matrouh, Mex, Nuzha, Salloum; Lower Nile Valley: Barrage, Borgash, Helwan, Kirdassa; Fayoum; Eastern Desert: Gubbet El-Bous, Wadi Digla, Wadi Hoff; Western Desert: Dakhla; Upper Nile Valley: Abu-Simbel, El-Minya; Sinai: El-Arish, Wadi Firan, Wadi Isla, Wadi Moueilah.

Dates of collection: January to October.

Spogostylum sordidum Sack, 1909.

Spongostylum antiopa Bezzi, 1925.

Distribution: AF: Oman. PA: Afghanistan, Egypt, Iran, Saudi Arabia, Tajikistan, Turkmenistan, Uzbekistan.

Egyptian localities: Coastal Strip: Mariout, Matrouh, Nuzha, Salloum; Eastern Desert: Wadi Digla, Wadi Hoff; Sinai: El-Arish.

Dates of collection: January to September.

Spogostylum tripunctatum (Pallas in Wiedemann 1818)

Anthrax difficilis Wiedemann in Meigen, 1820.

Spogostylum mystaceum Macquart, 1840.

Distribution: PA: Afghanistan, Albania, Algeria, Armenia, Austria, Azerbaijan, Bosnia-Herzegovina, Bulgaria, Croatia, Egypt, France, Greece (incl. Ithaca), Gruzia, Israel, Italy, Kyrgyz Republic, Libya, Macedonia, Malta, Moldova, Morocco, Russia, Spain, Switzerland, Syria, Tajikistan, Turkey, Turkmenistan, Ukraine, Uzbekistan.

Egyptian localities: Lower Nile Valley: Ezbet El-Nakhl, Mansouriah; Fayoum.

Dates of collection: March to June.

Spogostylum ventrale Bezzi, 1924

Distribution: AF: Eritrea, Ethiopia, Kenya, Oman, Yemen. PA: Egypt.

Egyptian localities: Sinai: Wadi El-Arbaein.

Dates of collection: May to July.

Spogostylum volitans Wiedemann, 1828

Distribution: AF: Sudan. PA: Egypt.

Egyptian localities: unknown.

Dates of collection: unknown.

\section{Conclusion}

As a final conclusion, a new species, Spogostylum niphasoides sp. nov. is here described from South Sinai, Egypt. This makes the total number of species within the genus Spogostylum in Egypt increases into 15 species.

\section{Acknowledgements}

I gratefully acknowledge the contribution of the famed British bee fly taxonomist late Dr. David Greathead to this paper. I am also indebted to Dr. Neal Evenhuis, Bishop Museum, Honolulu, Hawaii, USA for revising the manuscript.

\section{Funding}

No funding.

\section{Availability of data and materials}

Data supporting the conclusions of this article are presented in the main manuscript.

\section{Author's contributions}

This is a single author study. The author read and approved the final manuscript.

Ethics approval and consent to participate

Not applicable.

Consent for publication

Not applicable.

\section{Competing interests}

The author declares that he has no competing interests.

\section{Publisher's Note}

Springer Nature remains neutral with regard to jurisdictional claims in published maps and institutional affiliations.

Received: 14 August 2018 Accepted: 21 October 2018

Published online: 01 November 2018

\section{References}

Bezzi M (1912) Report on a collection of Bombyliidae (Diptera) from Central Africa, with description of new species. Trans Entomol Soc Lond 1911: 605-656

Bezzi M (1924) The Bombyliidae of the Ethiopian Region. British Museum (Natural History), London, p 390

Bezzi M (1925) Quelques notes sur les bombyliides (Dipt.) d'Egypte, avec description d'espéces nouvelles. Bull Soc Royale Entomol Égypte 8:159-242

Dils J, Ozbek H (2006) Contribution to the knowledge of the Bombyliidae of Turkey (Diptera). Linz Biol Beitr 38((1):455-504

El-Hawagry M, Gilbert F (2014) Zoogeographical affinities and faunal relationships of bee flies (Diptera: Bombyliidae) in Egypt. Zool Middle East 60(1):50-56. https://doi.org/10.1080/09397140.2014.892339

El-Hawagry MS (2002) Three new species of anthracine bee flies (Diptera: Bombyliidae) from Egypt. Zootaxa 111:1-8

El-Hawagry MS (2015) Catalogue of superfamily Asiloidea. Lap Lambert Academic Publishing, Saarbrücken, p 196

El-Hawagry MS, El-Moursy AA, Gilbert F, Zalat S (2000) The tribe Anthracini Latreille (Bombyliidae, Diptera) from Egypt. Egypt J Biol 2:97-117

Engel EO (1936) Bombyliidae. In: Lindner E (ed) Die Fliegen der palaearktischen Region. 4(3), vol 25. E. Schweizerbart, Stuttgart, pp 513-560

Evenhuis NL,Greathead DJ (2015) World catalog of bee flies (Diptera: Bombyliidae). Revised September 2015. Available from: http://hbs.bishopmuseum.org/ bombcat. Accessed 1 June 2018

Greathead DJ (1963) A review of the insect enemies of Acridoidea (Orthoptera). T Roy Ent Soc London 114:437-517

Greathead DJ (1980) Insects of Saudi Arabia. Diptera: Family Bombyliidae Fauna of Saudi Arabia 2:291-337

Hermann F (1907) Einige neue Bombyliiden der palaearktischen Fauna. (Dipt.). Z Syst Hymen Dipt7:193-202

Hesse AJ (1956) A revision of the Bombyliidae (Diptera) of Southern Africa. II [part]. Ann S Afr Mus 35:1-464

Hull FM (1973) Bee flies of the world. The genera of the family Bombyliidae. Bull U S Natl Mus 286:1-687

Kits JH, Marshall SA, Evenhuis NL (2008) The bee flies (Diptera: Bombyliidae) of Ontario, with a key to the species of eastern Canada. Can J Arthropod Identif 6:2-52

Loew H (1860) Bidrag till kännedomen om Afrikas Diptera [part]. Öfvers K Vetenskapsakad Förh 17:81-97

Macquart PJM (1840) Diptères exotiques nouveaux ou peu connus. Tome deuxième.-1 $1^{\text {re }}$ partie. N.E. Roret, Paris, p 135

Macquart PJM (1850) Diptères exotiques nouveaux ou peu connus. 4 supplément. Mém Soc R Sci Agric Arts Lille1849 61-96:309-479

Macquart PJM (1855) Diptères exotiques nouveaux ou peu connus. $5^{\text {me }}$ supplément. Mém Soc R Sci Agric Arts Lille(2) 1:25-156

Meigen JW (1820) Systematische Beschreibung der bekannten europäischen zweiflügeligen Insekten. Zweiter Theil. F.W. Forstmann, Aachen, p 363

Paramonov SJ (1957) Zur Kenntnis der Gattung Spongostylum (Bombyliidae, Diptera). Eos 33:123-155

Sack P (1909) Die palaearktischen Spongostylinen. Abh Senckenb Naturforsch Ges 30:501-548 
Walker F (1849) List of the specimens of dipterous insects in the collection of the British museum. Parts II-IV. British Museum, London, pp 231-1172

Walker F (1871) List of Diptera collected in Egypt and Arabia, by J. K. Lord, Esq., with descriptions of the species new to science [part]. Entomologist 5 : $255-263$

Wiedemann CRW (1818) Aus Pallas dipterologischen Nachlasse. Zool Mag 1(2):1-40

Wiedemann CRW (1828) Aussereuropäische zweiflügelige Insekten. Erster Theil. Schulz, Hamm, p xxxii + 608

Yeates DK, Greathead DJ (1997) The evolutionary pattern of host use in the Bombyliidae: a diverse family of parasitoid flies. Biol J Linnean Soc 60: $149-118$

Zaitzev VF (1997) On the Bombyliidae (Diptera) of Israel. III. Entomol Obozr 76: 892-913 [In Russian]

\section{Submit your manuscript to a SpringerOpen ${ }^{\circ}$ journal and benefit from:}

- Convenient online submission

- Rigorous peer review

- Open access: articles freely available online

- High visibility within the field

- Retaining the copyright to your article

Submit your next manuscript at $\boldsymbol{\nabla}$ springeropen.com 